\title{
CIDADES CAPITAIS E MOBILIDADE URBANA: O CASO DE BARCELONA
}

\author{
Adriana Gelpi ,Rosa Maria Locatelli Kalil, Tanise Spielmann \\ Universidade de Passo Fundo, Laboratório de Estudos Urbanos e Regionais \\ Mail: agelpi@upf.br \\ kalil@upf.br \\ tanise.arq@hotmail.com
}

\section{RESUMO}

O artigo trata das cidades capitais e da circulação urbana, conceituando termos de mobilidade e acessibilidade e discorrendo sobre a problemática do planejamento da mobilidade e da sustentabilidade dos transportes nas cidades contemporâneas. Parte do princípio da insustentabilidade do transporte coletivo e através de revisão bibliográfica foca o tema da necessidade do planejamento do transporte para as áreas urbanas e metropolitanas, da sua organização e da priorização do transporte público e coletivo frente ao veículo particular. Como estudo de caso, aborda o transporte urbano na cidade de Barcelona e seus principais modos de transporte coletivo: o metrô, o trem e o ônibus, contextualizando e diagnosticando cada modalidade. Apresenta para análise a Avenida Diagonal, concebida no Ensanche de Cerdá, em 1859, sua evolução e os projetos viários municipais implementados para a mesma. Conclui que a cidade ainda carece de um planejamento integrado para os transportes, mas coloca que em parcelas da Avenida Diagonal (trecho Glorias-Fórum), esta apresenta uma organização e integração modal exemplar.

Palavras-chave:Cidades; Mobilidade; Transporte Público; Barcelona

\begin{abstract}
This paper discusses about capital cities and urban traffic, conceptualizing terms of mobility and accessibility and considering the issue on transportation mobility and sustainability planning in contemporary cities. It focuses the issue of transportation planning for urban and metropolitan areas, its organization and yet, prioritizing public transportation before the private vehicle. It approaches urban transportation as a case study in Barcelona and its main public transportation means, to wit: metro, trains and bus, contextualizing, making reference and diagnosing each modality. It presents Diagonal Avenue for analysis, which was conceived at Ensanche de Cerdá in 1859, its evolution and road municipal projects for it. It concludes that the city still lacks an integrated planning for transportation, but it mentions that it presents a modal and ideal organization and integration in some parts of Diagonal Avenue.
\end{abstract}

Key words:Cities; Mobility; Public Transportation; Barcelona 


\section{INTRODUÇÃO}

As grandes cidades apresentam-se como espaços urbanos complexos, algumas vezes densos e compactos, e em outras, fragmentados e desarticulados, estendendo-se por grandes superfícies, como as regiões metropolitanas, as megacidades e as cidades globais. Estes tecidos sustentam dinâmicos fluxos de energia, fluxos de pessoas e materiais num modo contínuo, abrigando no seu interior, conflitos sociais e disputas pelo espaço melhor equipado.

Conforme Terradas (1996), à medida que a cidade se expande, existe a necessidade de se aumentar o transporte horizontal, de se incrementar os fluxos de materiais e energias, questão que compromete a qualidade de vida urbana. Este é o caso de Barcelona, capital da região da Catalunha, no noroeste da Espanha. Como uma grande capital regional, Barcelona já se encontra conurbada com várias povoações vizinhas, estendendo sua mancha metropolitana por uma grande superfície. Neste contexto, a administração municipal e as instituições metropolitanas devem organizar a mobilidade da metrópole gerenciando várias municipalidades e modalidades de transporte de passageiros, que buscam arduamente, disputar o espaço urbano e coletivo com o veículo particular.

O histórico sistema de metrô tem respondido pelo deslocamento de grande parte da população, mas novas tecnologias de veículos leves sobre pneus e trilhos tomam espaço, acirrando o debate entre os técnicos do planejamento dos transportes, que se posicionam frente às principais modalidades de transporte, mas a maioria destes técnicos ainda tem dificuldade de perceber, que o sistema de transporte de massa deve ser concebido juntamente com o planejamento do uso do solo urbano.

\section{MOBILIDADE URBANA E ACESSIBILIDADE}

Em um contexto de crescente expansão urbana e crescente número de deslocamentos diferenciados da população para realizar suas atividades cotidianas, cresce em importância o conceito de mobilidade urbana e de acessibilidade universal. O primeiro termo pode se entendido como a possibilidade de locomoção das pessoas no território e acesso ao espaço urbano e aos equipamentos desejados com facilidade e segurança.

Em relação à acessibilidade, o Decreto Brasileiro no 5.296, de dois de dezembro de 2004, coloca que a mesma está relacionada ao fornecimento da condição para utilização, com segurança e autonomia, total ou assistida, dos espaços, mobiliários e equipamentos urbanos, das edificações, dos serviços de transporte e dos dispositivos, sistemas e meios de comunicação e informação, por pessoa portadora de deficiência ou com mobilidade reduzida. A acessibilidade é um conceito complementar à mobilidade urbana, pois o poder de mover-se pela cidade utilizando qualquer meio de transporte só se valida se o cidadão também puder acessar seu objetivo, edificação ou espaço urbano desejado.

Para Herce (2009) o objetivo fundamental do planejamento da mobilidade urbana é conseguir que as pessoas voltem a caminhar para deslocamentos curtos, e usar o transporte coletivo para os deslocamentos mais longos. Neste sentido, o grande desafio da mobilidade urbana é lograr maior uso do transporte coletivo, sobretudo pelo incremento do preço dos combustíveis e pelo custo socioeconômico da congestão provocada pelo transporte privado.

Na figura 1 demonstra-se sobre ilustração de Herce (2007), a organização viária ideal e desejada para todas as cidades, com a priorização dos sistemas de transporte coletivo, da ciclovia e das áreas para pedestres, estas em diálogo com os espaços urbanos do entorno. 


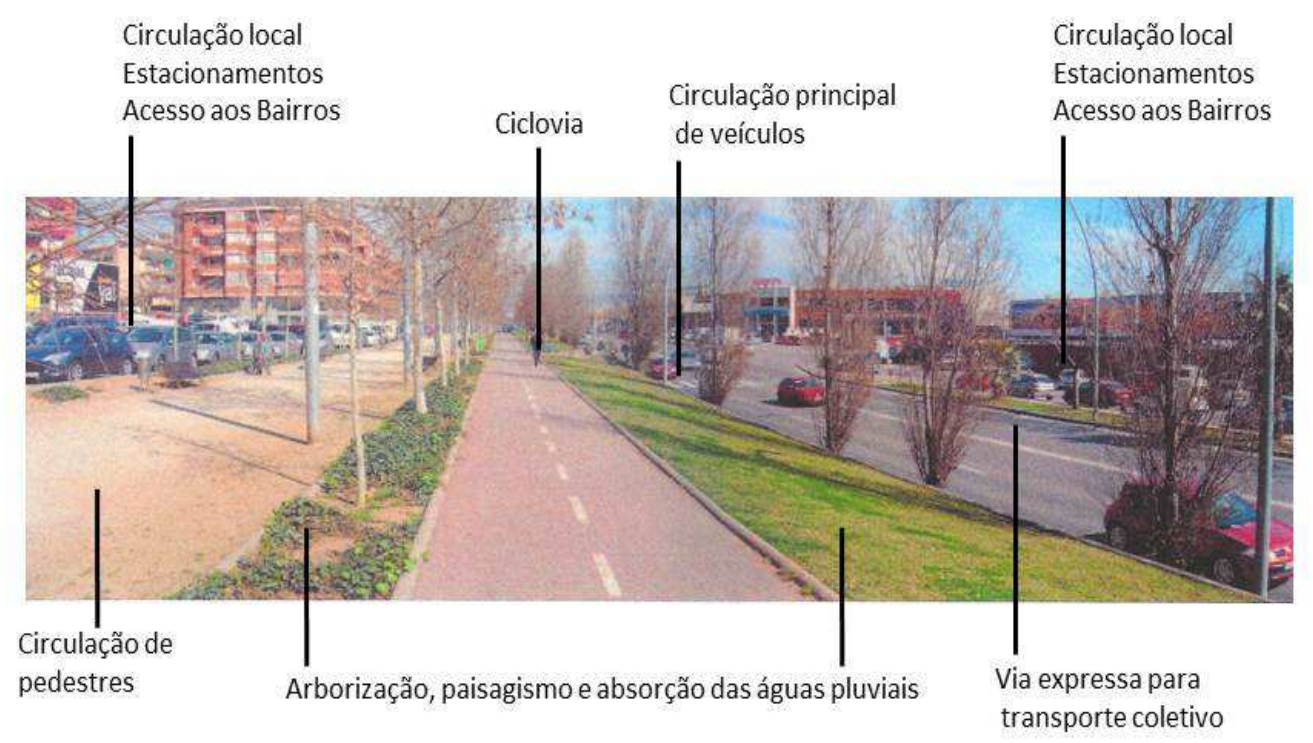

Figura 1. Organização dos espaços de mobilidade urbana.

Adaptado de Herce (2007)

\section{PLANEJAMENTO, MOBILIDADE E SUSTENTABILIDADE URBANA}

A produção do território atual, com sua capacidade urbanizadora, no caso brasileiro, incrementa a desigualdade social e não atende aos problemas da população, que vê o seu anseio da aquisição da casa própria como um esforço econômico quase impossível. Coloca também, que o urbanismo atual submete 0 cidadão a uma força centrífuga, que o expulsa à periferia urbana, espaço urbano carente e menos equipado.

Para Navas (2010), os problemas urbanos contemporâneos se devem, em boa parte, pela falta da real compreensão do problema que leve a uma planificação territorial e urbanística integradora das redes de mobilidade, ou da previsão destas vinculadas ao uso do solo. Pois as disfunções geradas pelo modelo de ocupação dispersa, que provoca mobilidade obrigatória e excessiva, baseada no transporte privado e na má gestão dos sistemas, gera efeitos urbanos negativos, desde a ineficiência energética até os problemas ambientais. A sustentabilidade urbana engaja-se nesta problemática, quando entendemos que para tal devemos utilizar de forma racional e responsável os escassos e limitados recursos do planeta, de maneira a não comprometer o desenvolvimento das gerações futuras. Neste sentido, a demanda por materiais de construção para erigir cidades e suas infraestruturas e a energia para movimentar os meios de transporte consomem insumos não renováveis, além de contribuir para emissão de gases que ocasionam o efeito estufa.

Na figura 2, sobre estudo de Font (2010), apresenta-se uma possibilidade de integração e setorização viária com a priorização da circulação de pedestres. Este estudo foi proposto pela equipe de profissionais do curso "Reforma de la Diagonal de Barcelona: Espacio público + transporte colectivo", para a Avenida Diagonal, realizado na ETSAB, em 2010. Neste artigo também analisaremos outras propostas para a avenida e a implantação de projeto municipal que setoriza e hierarquiza a mobilidade urbana em trechos da avenida. 


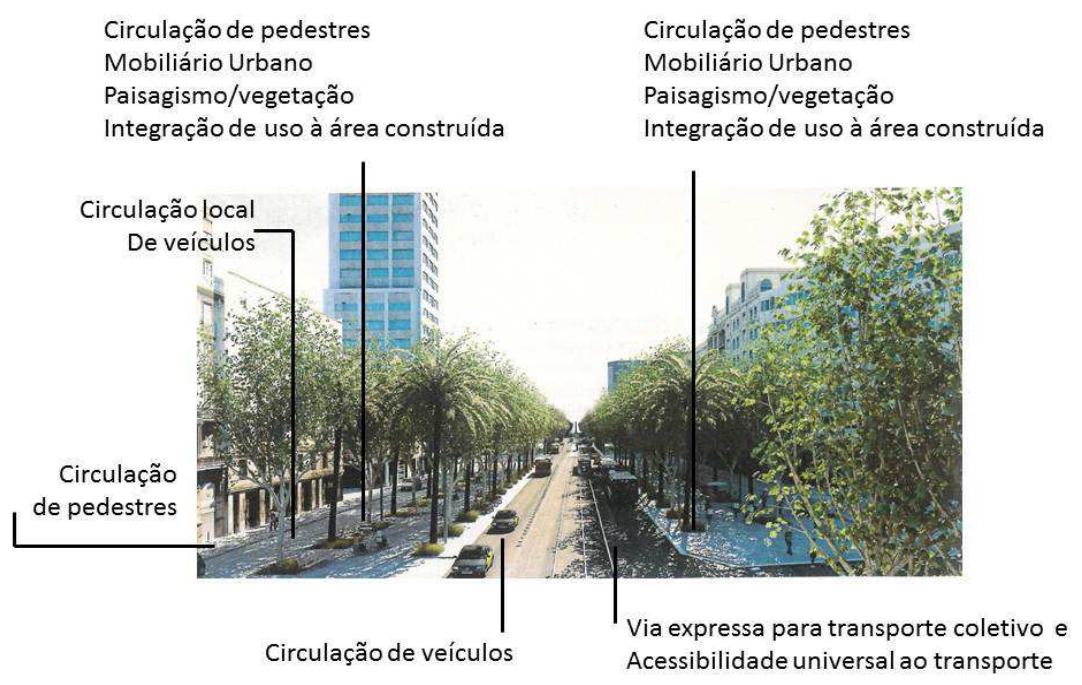

Figura 2. Organização da mobilidade urbana.

Adaptado de Font (2010).

\section{TRANSPORTE PÚBLICO PARA REGIÕES METROPOLITANAS}

As mudanças ocorridas na cidade se conjugam com novos hábitos sociais e culturais mais generalizados, como o fato do veículo privado adquirir um papel central na vida cotidiana dos cidadãos e do transporte urbano tornar-se cada vez mais problemático, em função de excessivas demandas, do esgotamento das infraestruturas, da falta de redes de transporte e sistemas modais adequados e integrados. Neste sentido é bem vindo o planejamento que objetive eliminar as viagens desnecessárias, que contemple os pedestres, o uso de bicicletas, o transporte público, o veículo privado e a distribuição racional de mercadorias, buscando uma mobilidade sustentável, esta entendida como aquela que se realiza em um determinado tempo, com custos razoáveis e minimizando os efeitos negativos sobre o entorno e a qualidade de vida das pessoas (Lei 9/2003 de 13/06/2003 de La Movilidad de Cataluña).

López de Lucio (2003) observa que a dotação e o suporte infraestrutural, especialmente a rede viária de alta capacidade, as redes ferroviárias e mais recentemente, as novas Tecnologias de Informação e de Comunicações são a base que possibilita, em muitos casos, e também direciona a transformação territorial. A mobilidade urbana, acompanhando a explosão das cidades causa um grande conflito frente ao planejamento urbano sustentável, que busca incentivar o transporte coletivo e público objetivando racionalizar e reduzir consumo energético e reduzir os impactos ambientais. A proposta de melhoria e do incremento do transporte público e o desestímulo ao transporte privado pode contribuir para uma qualificação do planejamento urbano e da mobilidade espacial, devendo esta premissa, ser anexada às políticas de mobilidade urbana realizada pelas administrações municipais.

Num contexto de crescente expansão urbana e crescente número de deslocamentos da população, para realizar suas atividades cotidianas, cresce em importância o conceito de transporte público de massa, integrando este sistema, o metrô, o trem de cercanias ou suburbano e o ônibus. Mas ainda de acordo com Solans (1971), a implantação de um sistema de transportes urbanos ou metropolitanos vai mais além do que uma simples obra de engenharia, pois as potencialidades desta infraestrutura são elementos geradores de grandes transformações urbanas e de valores de renda da terra. Para o autor, levando-se em consideração estes fatores, se poderá compreender o potencial do transporte público no processo urbano, e reestruturar, indiretamente através do controle e concepção adequada da infraestrutura, a dimensão da cidade. Como resultado, poderemos entender o efeito da mobilidade sobre a qualificação do solo para os diferentes usos, as densidades de assentamentos, a intensidades de uso de áreas centrais e as novas economias de localização a serem criadas, entre outros fenômenos urbanos.

\section{O CASO DE BARCELONA}

Barcelona é a cidade polo de uma extensa região metropolitana, às margens do Mediterrâneo. A cidade tem sido um paradigma urbano e arquitetônico em nível internacional, desde o projeto do Ensanche de Cerdà, em 1859, dos Jogos Olímpicos de 1992, e do Fórum Universal das Culturas, em 2004. 
No início do século XXI, a cidade conta com uma população de 1.600 .000 habitantes, e uma Região Metropolitana com 4.841.365 habitantes. Para Font (2007), essa região conforma-se como uma grande cidade, descontínua e heterogênea, integrada por um polo central, que é Barcelona, e por um conjunto de núcleos conurbados ao longo dos vales dos rios Llobregat e Besós. Estes núcleos se constituem em sistemas polarizados menores, com características diversas, e que no seu conjunto formam uma extensa malha desarticulada, poli-nucleada e escassamente reticulada.

$\mathrm{Na}$ história recente da região, Font (2007) aborda três momentos importantes da expansão urbana de Barcelona. O primeiro compreendido entre os anos de 1950 e 1975, foi o período da industrialização da Espanha, das correntes migratórias e demandas urbanas de todos os tipos. De 1975 a 1986, com a democratização e a crise energética aconteceu uma estabilização urbana, produzindo-se uma mudança na dinâmica demográfica com a descentralização residencial. Reduziu-se a população no centro histórico de Barcelona, produzindo-se uma mudança produtiva na cidade, que de caráter industrial, passou a prestadora de serviços, sendo que as indústrias se deslocaram para as cidades vizinhas.

O período 1986 a 2004, que corresponde ao período analisado neste trabalho, foi denominado por Font (2007) de período de recuperação econômica e urbanística através de grandes eventos, onde algumas peças urbanas previstas no Plano General Metropolitano (PGM) de 1976 foram implementadas. Neste momento se dará um grande salto na dimensão urbana de Barcelona, reforçando seu papel de cidade de serviços na malha metropolitana, e da requalificação de cidades do entorno, como Terrassa, Badalona, Castelldefels, Vikadecans, Mollet e Sant Sadurni, entre outras.

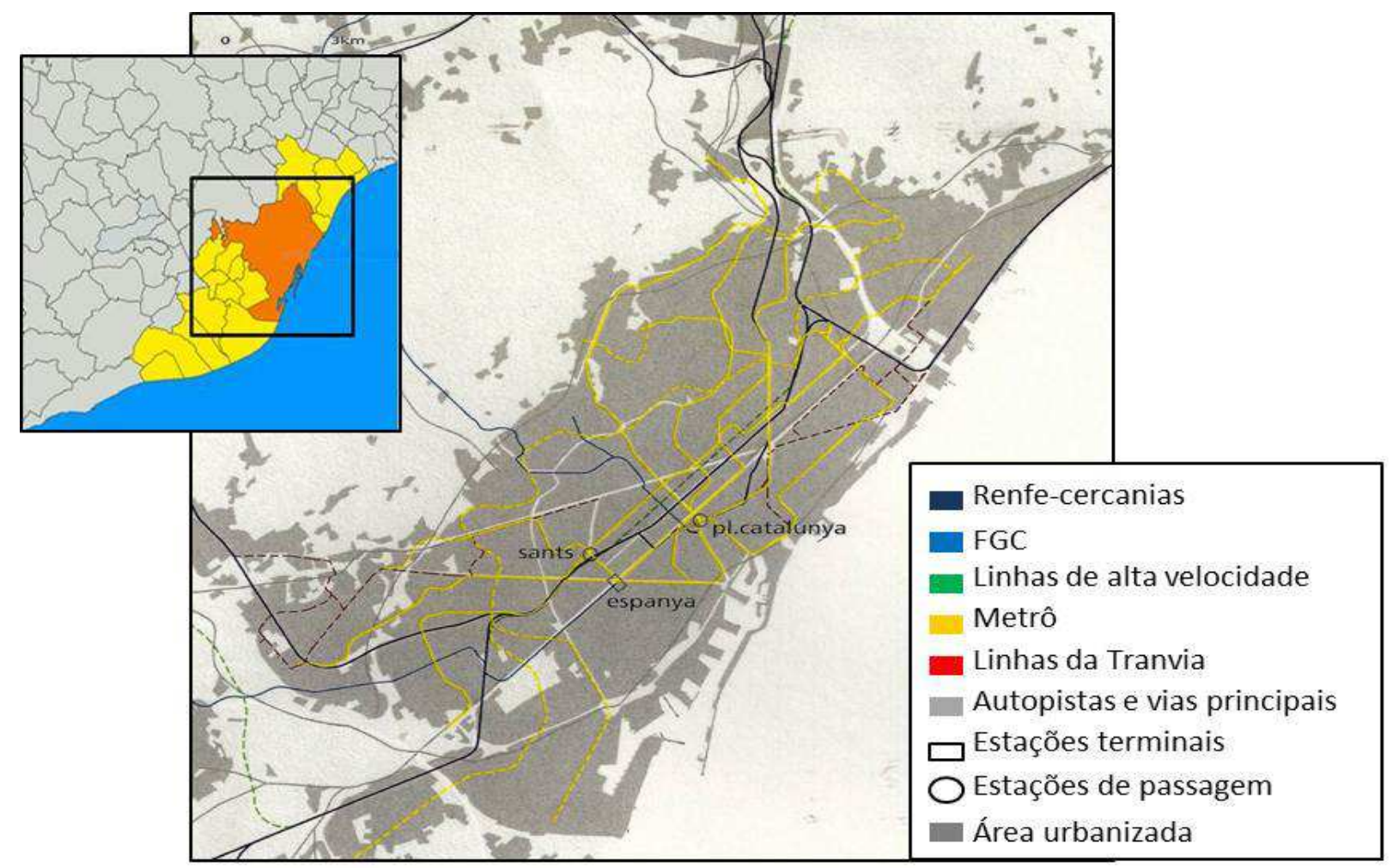

Figura 3. Região de Barcelona, municípios vizinhos e a principal infraestrutura viária da cidade.

Adaptado de Sort (2006) e ATM 2009.

Na figura 3 apresenta-se o mapa da região de Barcelona com seus municípios vizinhos e o mapa da infraestrutura viária da cidade, com os sistemas do trem de cercanias, das pistas de alta velocidade, das linhas de metrô, de bonde e de autopistas, sobre a área urbanizada. Pode-se concluir que atualmente, a Região Metropolitana de Barcelona apresenta-se como uma região polarizada pela capital, centro urbano que perde população para às áreas periféricas. Consolida-se a tendência generalizada da relocação das atividades produtivas, que buscam áreas mais acessíveis economicamente, para sua recolocação e barateamento da produção. Desta forma também se produz uma periferia seletiva, tanto da indústria como do setor terciário, acontecendo uma difusão dos serviços, antes localizados na cidade polo. 


\section{INFRAESTRUTURA E MOBILIDADE URBANA}

Em relação à infraestrutura e mobilidade, os padrões de relocação da indústria e dos serviços, junto com as dinâmicas demográficas de diminuição de população das zonas centrais em favorecimento das periferias urbanas, podem explicar porque se tenham produzido mudanças muito notáveis na mobilidade intermunicipal. Este fato acarretou a redução dos movimentos radiais em direção à Barcelona e o incremento dos movimentos de caráter transversal, com a sucessiva incorporação da área metropolitanas funcionais de territórios cada vez mais distantes.

Para o futuro precisa-se, de acordo com Font (2007) que o planejamento urbano faça frente a ineficiente disposição espacial dos usos e atividades, buscando uma reordenação que estruture e organize mais racionalmente território, reduzindo os deslocamentos desnecessários e aumentando as sinergias entre as diversas atividades. Para o autor, deve-se enfrentar o congestionamento atual das infraestruturas viárias e de transporte, que resulta ineficiente em relação à acentuada mobilidade multidirecional através da melhora da infraestrutura existente. Isto deve ocorrer, principalmente, na escala urbana intermediária e especialmente em relação aos transportes públicos, permitindo uma localização mais racional das novas atividades e daquelas com maior concorrência pública.

Volta-se, então, às considerações de Solans (1971), quando o autor aborda a importância e o potencial do transporte público e sua infraestrutura no processo de estruturação e reestruturação urbana. Em relação a estas infraestruturas, vamos comentar o desempenho recente dos principais modos de transporte que fazem parte da composição da mobilidade urbana de Barcelona e áreas de sua abrangência.

\subsection{0 metrô}

As cidades contemporâneas têm utilizado vários sistemas de transporte coletivo, mas o metrô tem se apresentado como um sistema indicado para o deslocamento de grande número de pessoas, por sua velocidade comercial, capacidade de organizar a mobilidade massiva de passageiros com regularidade e segurança, independentemente das ocorrências da circulação viária de superfície. Em função destas vantagens, o número de cidades que tem utilizado o sistema de transporte de metrô, aumentou das 20 existentes no início do século XX para mais de 100 na atualidade, sendo o processo crescente.

O sistema de linhas de metrô de Barcelona data os anos 1920, e no seu conjunto, a rede de metrô e de trens suburbanos expressa o caráter litorâneo da cidade que se desenvolveu seguindo o Plano de Ensanche de 1859. As linhas e as estações de transbordo acompanham esta disposição geral convergindo para a centralidade conformada pelo Ensanche. Mas no seu desenvolvimento, a cidade precisou multiplicar centralidades, enquanto que a rede ficou relativamente estagnada, desde os anos oitenta, mantendo uma disposição arbórea, que não corresponde com a dimensão metropolitana nem com os corredores de mobilidade da cidade.

O Plano de Infraestruturas de Transportes de 1992, o PIT, esboçou a política dos transportes para os anos de 1995-2002, e sob o ponto de vista de Parcerisa e Ventós (2002), penalizou o sistema de transporte de metrô, ao concebê-lo, assim como ao trem, como uma "tecnologia extrema", dentro de um leque de modalidades de transporte urbano, que se inicia com o ônibus. Eles observam que tal fundamentação requer subsídios, pois o estabelecimento a priori, de um sistema em detrimento de outro não procede, se entendermos que as duas modalidades de transporte são por definição, sistemas integrados e contínuos.

A recente decisão de construir uma nova linha de metrô de ronda (Linha 9) aponta duas tendências de mudança importantes: desenvolver o sistema de redes através de novas linhas, e não somente prolongar as que já estão em serviço e multiplicar as estações de interconexão com uma disposição menos central, para projetar um traçado menos redundante pelo centro da cidade, diversificando a rede e mudando o caráter radial e centenário da mesma.

Na figura 4 apresenta-se o mapa esquemático do projeto da rede ferroviária integrada de transporte de Barcelona com o traçado eetapas do projeto da linha 9 que deverá ser implantado em grande profundidade. Esta linha pretende qualificar o sistema, rompendo o tradicional traçado de "leque" conversor ao Ensanche e abranger em traçado distinto, maiores distâncias participando do complexo sistema de integração modal de "La Sagrera". 


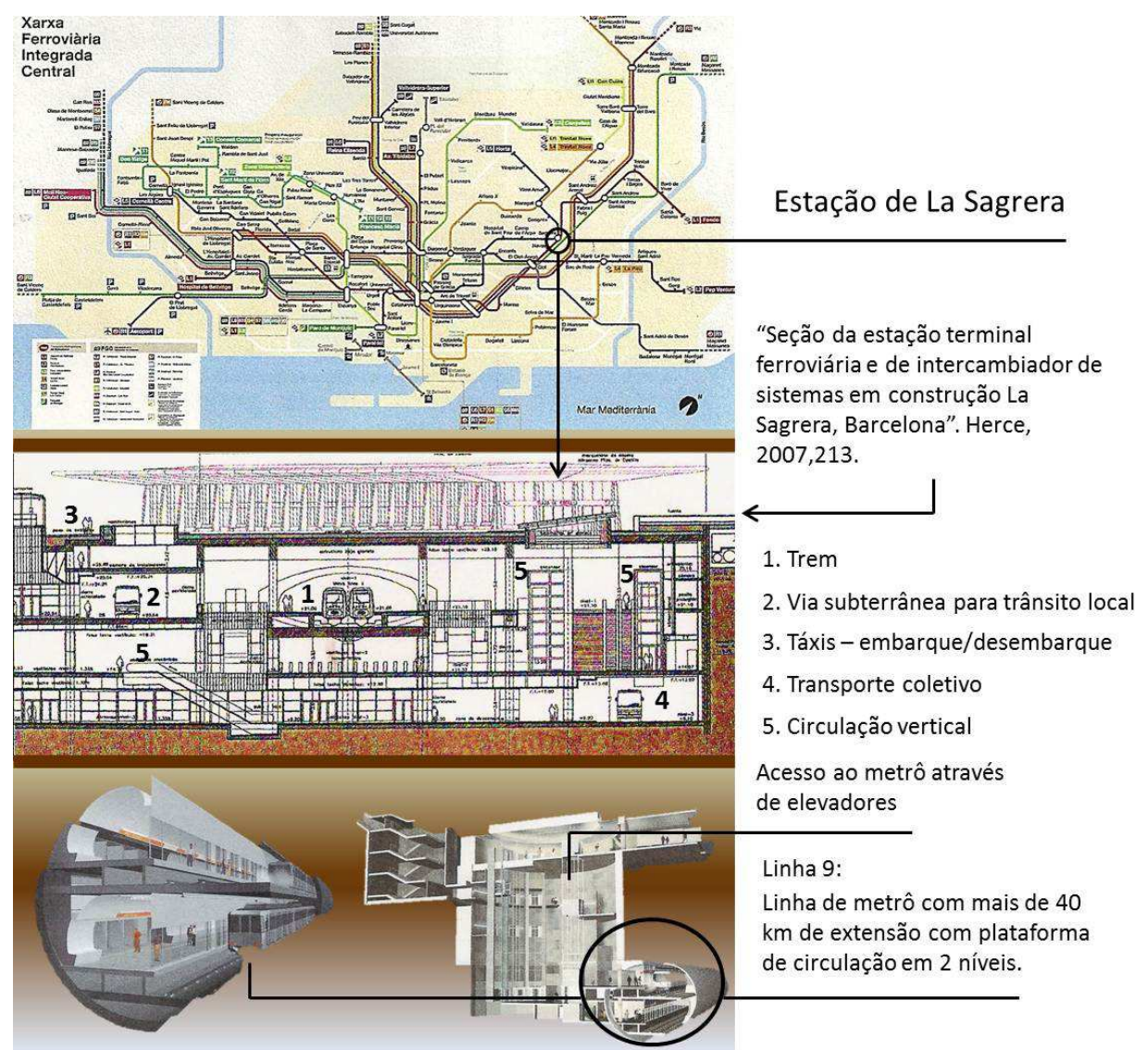

Figura 4. Sistema ferroviário integrado de Barcelona e etapas do projeto da linha 9 Adaptado de TMB, Herce, 2007 e TMB (2009).

De acordo com Parcerisa e Ventós (2002) as realizações até agora apresentam o sistema de metrô como um território globalmente servido, entendendo tal situação como a de ter uma estação a um raio de menos de 500 metros. Isto se aproxima de uma área de continuidade urbana densa dentro da metrópole, mas ao mesmo tempo, deixa grandes áreas desatendidas e que deveriam estar servidas, em função de sua densidade e centralidade em relação à metrópole, como a Zona Franca, Montjüic, a Ronda de Mig, Sant Just e Montigalá.

Em relação ao planejamento e investimentos em infraestrutura de mobilidade urbana, Parcerisa e Ventós (2002:145) ressaltam que o metrô deve dar resposta à estrutura da cidade e a seu funcionamento consolidado, mas que por outro lado, o metrô é uma opção de futuro, um poderoso instrumento de melhora e progresso e por tanto, deveria sintonizar-se, preferentemente, com os fenômenos mais dinâmicos da sociedade, o qual significa, na sua implantação, impulsionar a difusão de serviços e de urbanização, em áreas emergentes.

Na figura 5 apresenta-se o mapa da área urbana de Barcelona, as linhas e as áreas servidas pelo sistema de metrô, assim como os espaços urbanos não atendidos por este transporte de massa. Áreas e equipamentos urbanos importantes da expansão urbana e modernização da cidade, como o porto e o aeroporto, ainda não estão atendidas pelo metrô. 


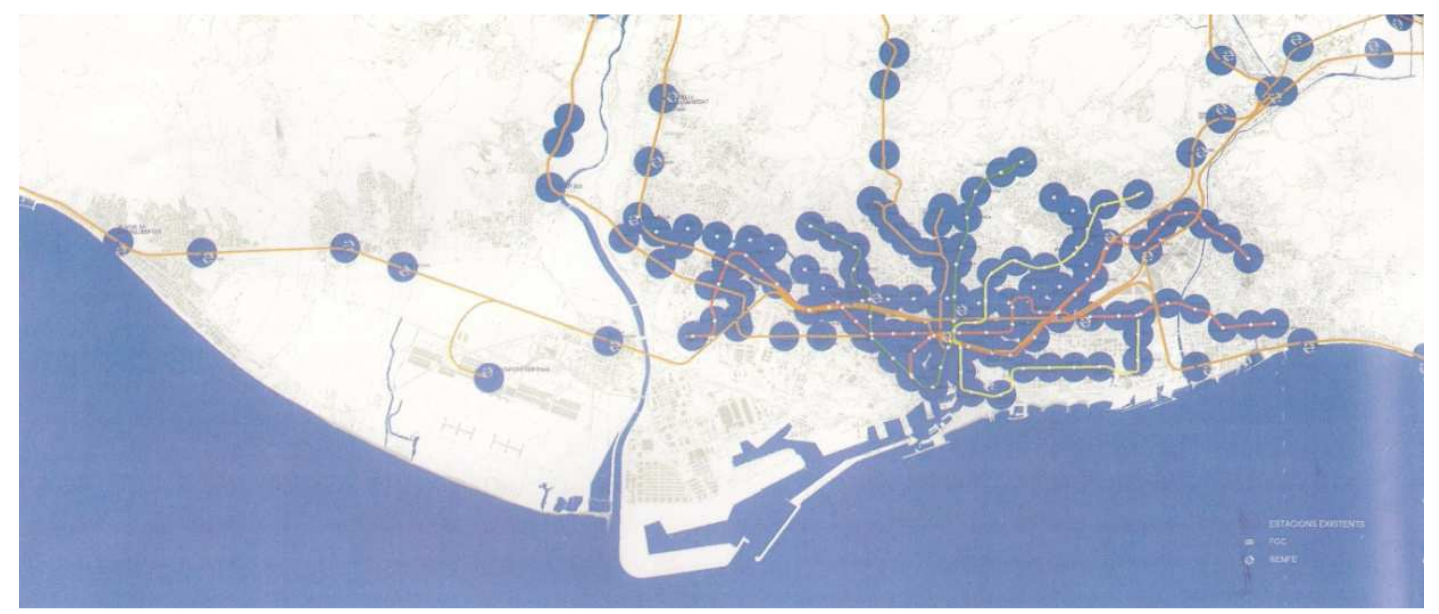

Figura 5. Mapa das áreas atendidas e desassistidas pelo sistema de metrô.

Parcerisa e Ventós (2002).

\subsection{0 trem urbano ou de cercanias}

No contexto das grandes urbanizações, Parcerisa e Ventós (2002) relatam que a crescente interação entre as cidades e suburbanização da residência tem comportado maior intermodalidade entre o metrô e os sistemas de trens urbanos. Neste processo ainda recente, de maior utilização, integração e relevo dos trens de cercanias, foi decisivo que estes trens urbanos avançassem no planejamento dos seus sistemas e investissem em tecnologia, adotando a frequência, a regularidade e as tecnologias do metrô. Na utilização do sistema integrado entre trens e metrôs, os trens suburbanos praticamente se converteram em metrôs regionais, sendo que a sinergia entre a rede de metrôs e de trens tornou-se possível, aparecendo os efeitos exponenciais do sistema, como a otimização dos serviços dos trens para mobilidade metropolitana, os avanços tecnológicos e de logística e a diversificação da energia propulsora.

Os anos 1980 e 1990, para Prat (1985) foram um período de supressão de barreiras físicas em Barcelona, que sempre se constituíram como um elemento negativo ligado ao trem. Fala-se das passagens em nível, da falta de segurança entre a infraestrutura férrea e a cidade, da existência de grandes áreas de domínio público e baldias dentro da área urbanizada, da desintegração do tecido urbano e da divisão do território. A eliminação destas barreiras através do soterramento parcial ou total de passos em diferentes níveis contribuiu para qualificar a cidade, especialmente com a eliminação do ramal da Marina, para a urbanização da orla marítima. Na figura 6 apresenta-se o traçado esquemático do sistema ferroviário de Barcelona, localizando-se a Estação de Sants. A Estação, situada em área central a cidade e em zona excêntrica à região metropolitana, já se encontra congestionada pelo fluxo de passageiros e veículos.

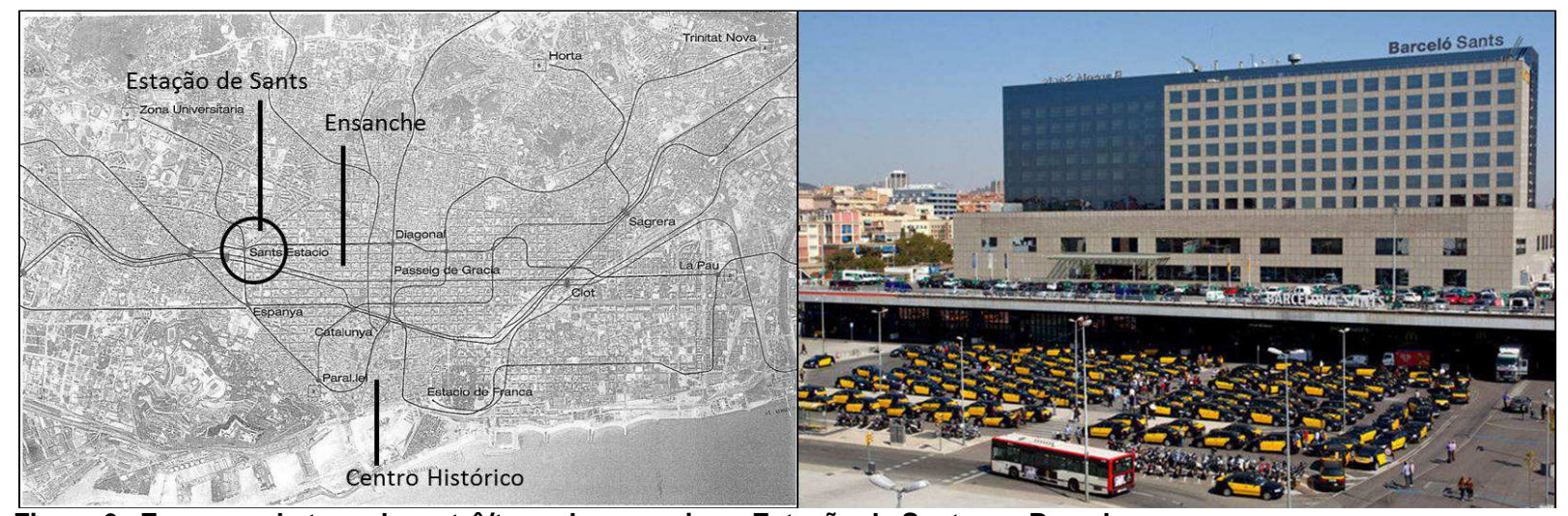

Figura 6. Esquema do traçado metrô/trem de cercanias e Estação de Sants em Barcelona Adaptado de Parcerisa e Ventós, (2002) e Lavanguardia,( 2012).

O trem tem participado do crescimento das relações metropolitanas através da melhora dos seus serviços, mas apesar disto, os autores que abordam o tema são unânimes em colocar que nos últimos anos não houve incremento das áreas servidas ou da implantação de novos pontos de interconexão com o metrô, 
apenas a qualificação dos serviços existentes. As linhas que chegam à Barcelona seguem traçados de uma lógica ferroviária antiga, com terminais nas Praças da Catalunha e Espanha, localizadas no mesmo lugar desde a fundação.

Prat (1994), ao abordar o conflito sobre o planejamento e concepção de sistemas de transportes para Barcelona, também coloca que "existe uma falta de consenso definitivo sobre as atuações ferroviárias futuras no âmbito de instituições e empresas responsáveis por sua planificação", tornando a análise e o planejamento sobre a inserção da rede ferroviária no entorno territorial tão complexo com a Região Metropolitana de Barcelona, especialmente frente a vários projetos e iniciativas dos mais variados tipos.

\subsection{A rede de ônibus}

De acordo com a EMT (2011), a rede de ônibus de Barcelona se apresenta como uma rede mista, composta por um sistema ortogonal ou em grelha ao qual se somam varias linhas no sentido diagonal. No sistema, algumas linhas passam pela área central, sendo o principal objetivo da trama dar uma cobertura uniforme à cidade, incorporando algumas linhas radiais. Algumas linhas principais são alimentadas por linhas secundárias ou prolongações, que correspondem ás linhas de bairro, o transporte de proximidade. Esta trama deve atender uma parte importante da mobilidade metropolitana da região, que se produz no âmbito metropolitano, especialmente por causa da atração e da importância da cidade de Barcelona como local de trabalho para àqueles que residem em outras cidades.

Para Parcerisa e Ventós (2002) o Plano de Infraestruturas de Transportes de 1992 valorizou a o ônibus ao penalizar o sistema de transporte de metrô, concebendo-o como uma "tecnologia extrema". Neste sentido, de acordo com o relatório da AMB (2011), visualizam-se os esforços institucionais para investir no transporte público de ônibus para torná-lo um modelo ótimo de sustentabilidade, mais eficiente, atrativo e acessível à população através de maior cobertura da rede, mais frequência de passagem e maior atenção aos transbordos.

Fisicamente, a implantação de pistas exclusivas para ônibus, onde também podem circular os taxis, permite maior velocidade ao sistema, trazendo segurança para a população e para o próprio sistema de transporte coletivo. Outros investimentos buscaram a renovação da frota, com veículos que utilizam energias alternativas aos carburantes fósseis, e com a utilização do piso baixo, que facilita à acessibilidade dos passageiros. Investiu-se também na climatização e a aquisição de uma crescente frota de veículos articulados, aumentando a capacidade veicular. Implantou-se a informação ao usuário em paradas inteligentes em forma de iBus (informação através da internet) e mBus (informações através do telefone móvel).

Na figura 7 apresentamos o sistema e o percurso do transporte urbano realizado pelos ônibus na cidade de Barcelona. Percebe-se a grande trama viária no qual se constitui, gerando a crítica, pelos estudiosos do transporte, que a mesma deveria ser racionalizada, evitando-se a superposição de linhas e a duplicidade de serviços.

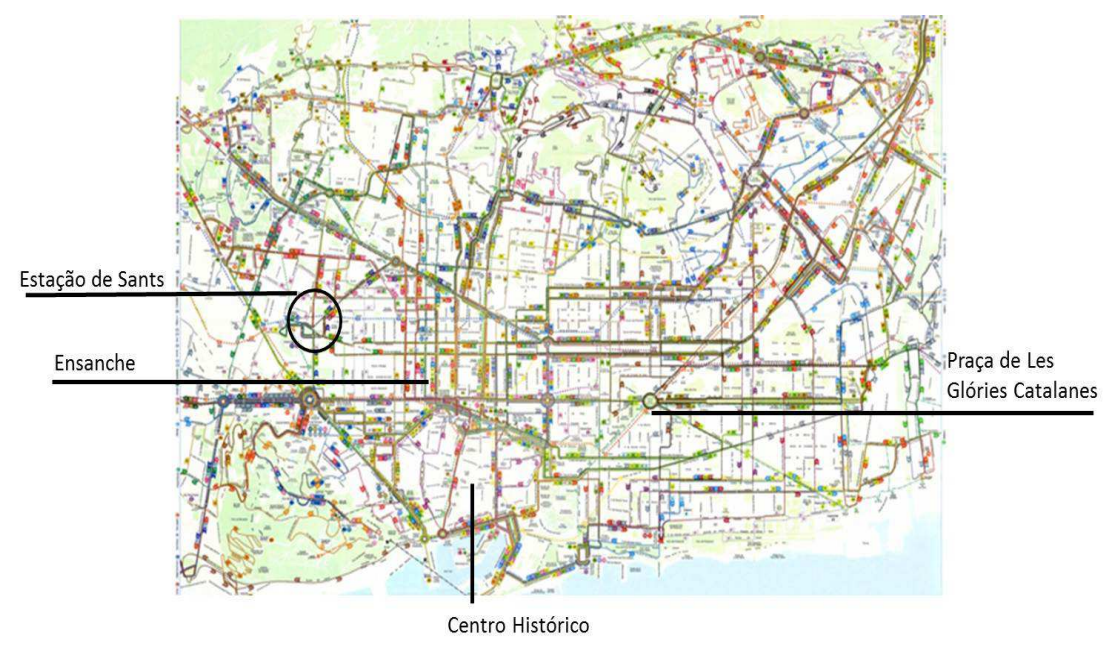

Figura 7. Sistema de linhas de ônibus de Barcelona

Mapa metro de Barcelona (2013). 
Depois de analisar o desenvolvimento das linhas de metrô e do relatório da AMT (2011) para os ônibus em Barcelona, as palavras de Prat (1994) que colocam a existência de um conflito sobre o planejamento e concepção de sistemas de transportes adequados para Barcelona, ficam mais claras. Para o autor, a priorização do sistema de ônibus em detrimento do metrô, pretendida pela instituição se expressa apenas, na criação de novas linhas secundárias e na qualificação da estrutura do sistema, mas não o concebe como um gerador de espaços urbanos.

De acordo com a AMB (2011), uma gestão contemporânea e mais centralizada dos recursos operativos do setor trouxe economia e inovação ao sistema, mas apesar destas implementações, ainda não se projetou um serviço de ônibus urbano de altas prestações, que opere em rede com o metrô e os bondes, numa verdadeira integração modal. Os dados fornecidos pelo relatório da AMB (2011) revelam ainda, uma baixa utilização global deste meio de transporte, talvez por historicamente, o metrô ter sido o transporte mais popular dentro da área urbana de Barcelona.

Na figura 8 apresentam-se imagens da qualificação da infraestrutura do sistema de ônibus de Barcelona, do mobiliário com estratégias de sustentabilidade e de equipamentos informatizados que incentivam e agilizam o uso do transporte coletivo.

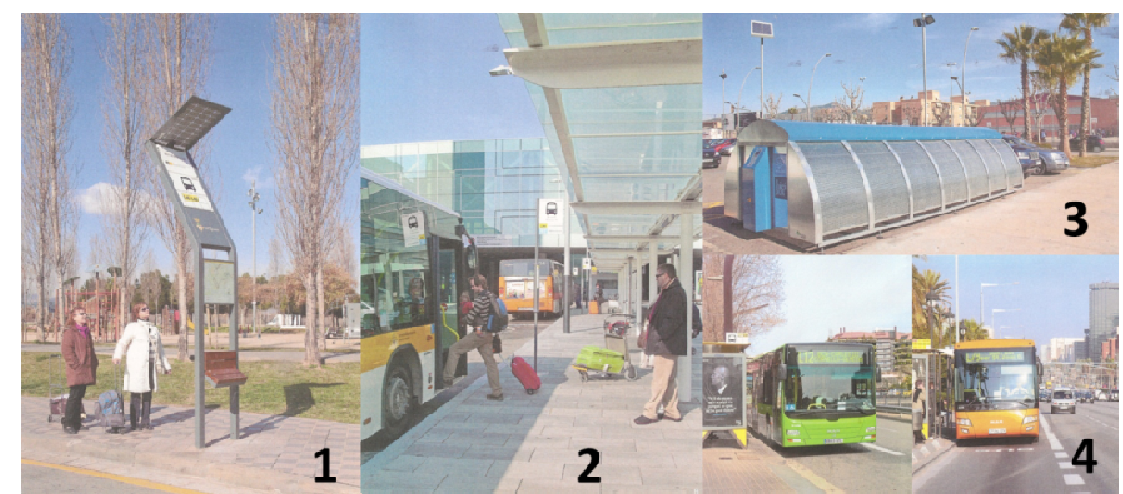

Figura 8. Qualificação da infraestrutura dos sistemas de ônibus em Barcelona. 1: paradas solares, com pantalhas digitais para facilitar a comunicação com os usuários. 2: Acessibilidade facilitada com o rebaixamento veicular. 3 . BICIBOX para guarda e segurança das bicicletas do passageiro em integração modal. 4: Pista exclusiva para o transporte coletivo.

Área Metropolitana de Barcelona (2011).

\section{INTEGRAÇÃO E ORGANIZAÇÃO MODAL: A AVENIDA DIAGONAL COMO ESTUDO DE CASO}

Mackett (2001) coloca que apesar da existência de várias opções de transportes em operação nas grandes cidades do mundo, a falta de planejamento dos sistemas como um sistema integrado não tem permitido o aproveitamento da potencialidade de cada um dos modos de transporte disponíveis. Acredita-se que com um sistema operando de forma adequada e integrada, seria possível inclusive, incentivar a transferência modal de usuários do automóvel particular para outros modos de transporte mais sustentáveis, reduzindose impactos na rede viária e no ambiente urbano.

Sob esse conceito, torna-se fundamental um maior entrosamento e a integração entre os vários sistemas de transporte público, de forma a oferecer aos usuários mais opções viáveis de deslocamento, produzindo-se também menores impactos à rede viária. A integração modal através de um elemento que conecte os meios de transporte coletivo pode ser um nó articulador de varias redes, que facilite a conexão entre diferentes meios de transporte de passageiros. Os terminais integradores ou ainda os sistemas integrados agrupam uma variedade de meios de transporte num mesmo lugar ou num mesmo sistema viário, como os pedestres, os ônibus, os bondes, os metrôs, os trens e os automóveis.

O planejamento de operação modal integrada pode contribuir para recuperar a eficiência operacional perdida ou nunca ganha nas grandes cidades do mundo. Esta integração teria como vantagem a expansão dos serviços além da zona de abrangência de uma simples linha de transporte, aumentando o número de usuários atendidos. Representaria também um novo nicho de mercado, contribuindo para 0 desenvolvimento de regiões estagnadas com geração de trabalho e renda. 
Parcerisa e Ventós (2002) colocam que a operações de intermodalidade se concretizam através da conexão dos traçados da alta velocidade com a organização dos espaços que facilitem o enlace com os transportes de superfície ou com redes mais capilares. As estações se convertem em espaços arquitetônicos de grande interesse e atualidade. Não se limitam somente a organizar o movimento, mas se constituem em autênticos nós de atividade. Atividades anexas como o comércio e o intercambio geram âmbitos secundários de centralidades que seguidamente se acompanham de remodelações urbanas no seu entrono. Este é o caso da Avenida Diagonal em Barcelona, avenida que tem sido protagonista de boa parte do crescimento da cidade, desde o projeto de expansão urbana do Ensanche de Cerdá, que em 1859 previa um crescimento da cidade através de sistema urbano independente, mas conectado com o tecido medieval e estruturado sobre quatro grandes avenidas, a Avenida Diagonal, a Meridiana, a Gran Via e o Paseo de Gracia.

Conforme Magrinya (2010, p. 13), Cerdá desenhou o Ensanche a partir de uma quadrícula conectando-a ao território através de algumas vias "transcedentais", que conectavam o ensanche com o território metropolitano. Segundo a nomenclatura de Cerdá, as vias transcendentais são aquelas vias que conectam a cidade ao mundo. No projeto de 1859, desenhou cinco vias: a Meridiana, a Paralela, a Gran Via, a Diagonal e o Paseo de Gracia. Estas vias tem a característica de ter uma seção de $50 \mathrm{~m}$, que permite acolher todos os modos de transporte, entre eles o bonde.

Na figura 9 apresenta-se o mapa do Ensanche de Barcelona, projetado por Cerdà em 1859, localizando-se a Avenida Diagonal, uma das cinco vias estruturadoras da proposta urbana concebida pelo projetista, e analisada neste trabalho.

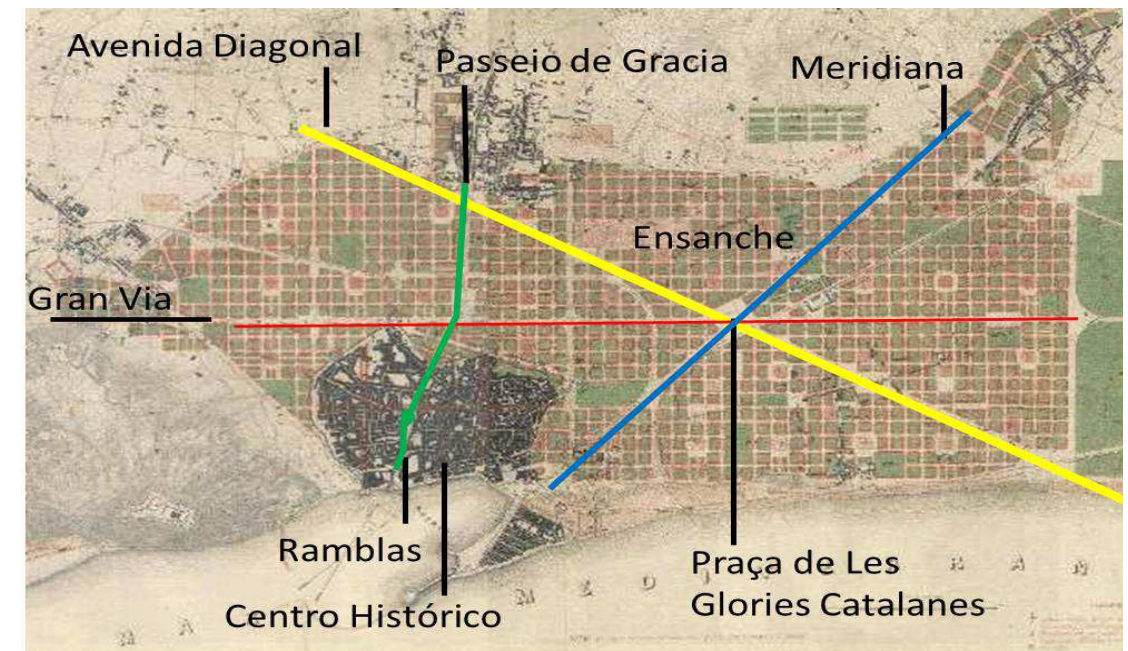

Figura9. Ensanche de Cerdá com a Avenida Diagonal.

Muzás (2011).

A Avenida Diagonal é hoje um grande articulador urbano, espaço viário que corta a cidade do noroeste, desde a Ronda de Dalt, até o sudeste, onde se integra à Ronda do Mar, junto ao Mediterrâneo. No encontro com as Rondas a avenida já apresenta um novo tipo de organização viária, que busca atender ás preocupações de Cerdà e vinculá-las às preocupações contemporâneas quanto à circulação de pedestre e a setorização viária. Entretanto o trecho intermediário e central da cidade é mais problemático, por estar consolidado e não apresentar tais características de planejamento. O trecho intermediário, de acordo com Font (2010) se apresenta sobre uma trama ordenada do Ensanche Cerdá, onde se detecta uma desordem dos fluxos e dos movimentos dos diferentes usuários. Não existe uma especialização viária e a via se apresenta com alto nível de contaminação acústica e escassez de espaço público na área central. Magrinya (2010) coloca que as queixas maiores sobre a avenida são a presença massiva dos automóveis e o nível elevado de ruído. Além disso, este trecho se encontra ocupado principalmente pelo trafego privado que tomou, gradualmente, o espaço dos pedestres.

A prefeitura de Barcelona propôs duas alternativas de projeto para a revitalização da área central desta avenida, colocando os mesmos em consulta à população. Da mesma forma, o tema tem suscitado estudos acadêmicos, que resultaram em interessantes alternativas para a Avenida Diagonal, mas em todos os estudos e projetos, o uso do transporte público e coletivo, a setorização das modalidades de transporte e o significativo investimento na área de uso dos pedestres foram fatores primordiais. As duas propostas da prefeitura para qualificar o trecho central da Avenida podem ser basicamente descritas como: 
1) O "Boulevard", onde se mantém o traçado básico da via, mantendo a arborização existente e as dimensões gerais das diferentes faixas dedicadas aos pedestres e ao trânsito, sendo que 0 sistema de alta velocidade se localizaria no centro da avenida, em plataforma única para o ônibus ou o bonde, e as laterais para pedestres, automóveis e bicicletas.

2) O Passeio Central ou Rambla, que explora a área central da via para pedestres e bicicletas, deixando as laterais para o transporte rápido e para os veículos privados, reorganizando a vegetação, mas deixando mais versátil a integração dos veículos rápidos às vias locais.

$\mathrm{Na}$ figura 10 apresentam-se as duas propostas elaboradas pela prefeitura de Barcelona para a qualificação do trecho central da Avenida Diagonal. Imagem 1, o "Boulevard" e imagem 2, a "Rambla".

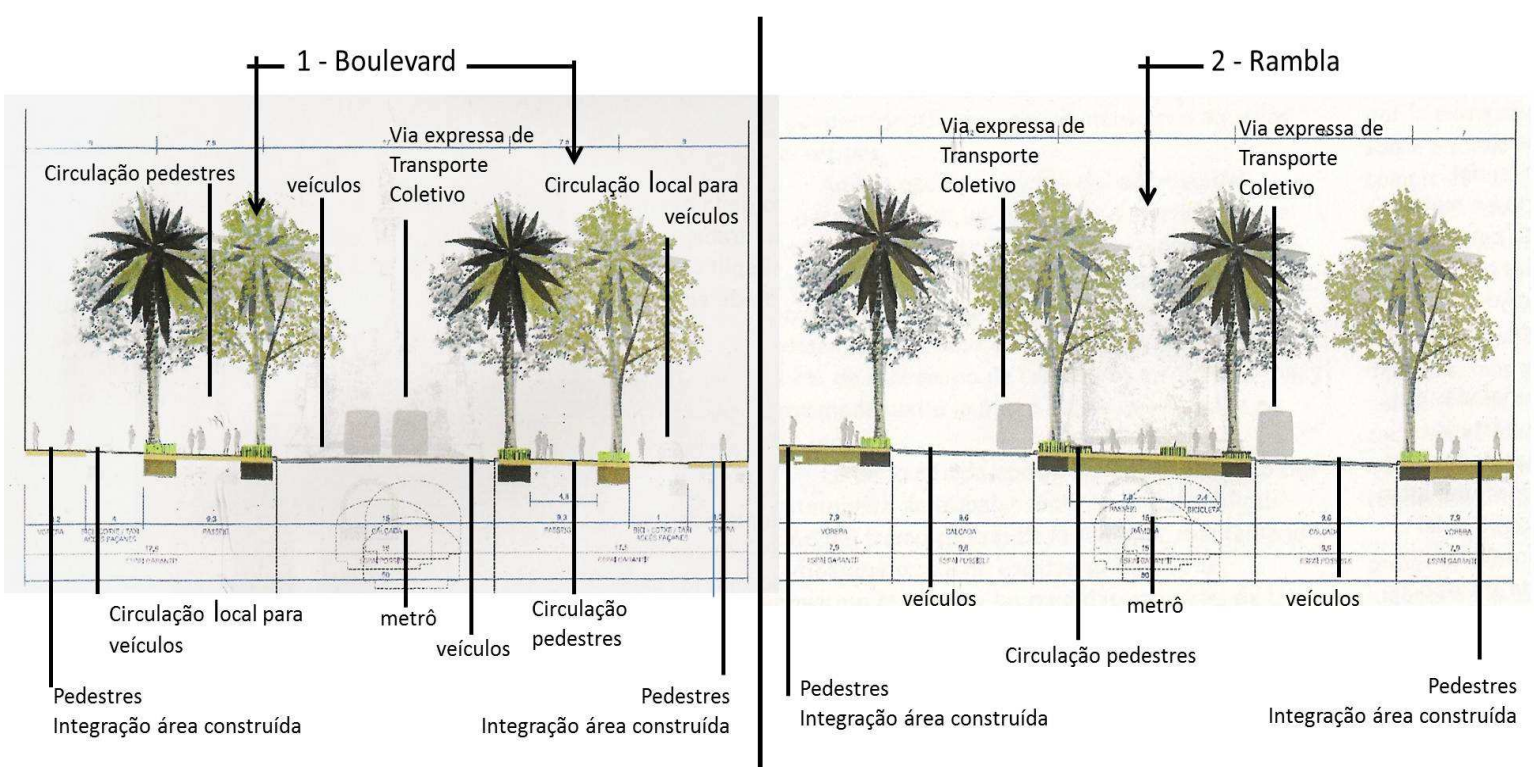

Figura 10. Proposta 1e 2: O Boulevard e o Passeio Central ou Rambla.

Adaptado de Font (2010).

Font (2010) coloca que as opções de proposta apresentadas pela prefeitura partem do objetivo de recuperar pelo menos $50 \%$ da superfície para o pedestre, e eliminar, em função do investimento no transporte público em superfície, e da futura linha 9 do metrô, boa parte do transito de veículos privados na avenida, ou seja, aproximadamente a metade do fluxo viário de cada direção. O autor observa que na sua síntese expositiva, a prefeitura não aborda o tratamento dos vários cruzamentos da avenida com as vias transversais nem das paradas intermodais de ônibus, carecendo ainda o projeto, de uma visão mais metropolitana, para encarar a avenida e suas estâncias de pedestres como "um grande salão urbano".

Mas mesmo assim o transporte público em Barcelona vem recebendo intervenções que qualificaram o sistema (Brito, 2010). Uma das principais causas dessa eficiência está na adoção de um modelo integrado de vários modais de transporte: o trem, o metrô, o ônibus e o Veículo Leve sobre Trilhos, o VLT, atendendo os bairros e contribuindo para a redução do número de automóveis a circular na cidade, uma das principais preocupações das cidades contemporâneas.

O projeto de parte da Avenida Diagonal (em direção ao Mediterrâneo), ainda sobre o antigo e perene traçado concebido por Cerdá, no espaço compreendido entre a Praça das Glories e o Edifício Forum, de acordo com Brito (2010) mostra a concepção de um novo espaço urbano com a previsão da integração de vários sistemas modais num mesmo espaço viário e várias integrações intermodais ao longo de seu percurso. Neste trecho, o espaço central da Avenida está destinado à circulação dos pedestres, como prevê a proposta tipo "Rambla".

Na figura 11, elaborada por Brito (2010), apresenta-se a organização viária implantada na Avenida Diagonal, no trecho compreendido entre a Praça das Glories e o Edifício Forum. Observa-se a organização dos sistemas modais com a clara priorização do transporte público coletivo e das amplas circulações reservadas para os pedestres. Neste trecho da avenida, foi implantado o projeto que mantém a principal 
circulação de pedestres entre as vias de circulação do transporte coletivo e dos veículos em geral, em uma releitura do modelo de Rambla.



Figura 11 - Seção da Estação Ca l'Aranyó comentada. Avenida Diagonal, Barcelona. Adaptado de Brito, 2007.

De acordo com Font (2010), a Avenida Diagonal se apresenta como um elemento articulador da área urbana de Barcelona, integrando as Rondas, sendo que o trecho compreendido entre as Praças Francesc Maciá e a das Glóries se apresenta como insuficiente para suportar o trânsito que carrega mais de 400.000 viagens por dia, através dos mais variados meios de transporte. A esta congestão viária somam-se os conflitos entre pedestres, bicicletas e patinadores nos passeios laterais, repletos de motociclos e bicicletas estacionados e a estreiteza de algumas calçadas que apresentam uma largura menor daquelas do Ensanche. Para o autor, este trecho, entre os sistemas urbanos de Besós e Llobregat se apresenta como um novo centro urbano e metropolitano, devendo ser tratado como tal.

Poderíamos dizer que a Avenida Diagonal se apresenta hoje com três grandes setores bem definidos, sendo o primeiro da Ronda de Dalt até à Praça Francesc Maciá, o segundo trecho, da Praça Frances Maciá até a Praça das Glóries e o terceiro trecho, da Praça das Glories até a Ronda Litoral, sendo o trecho intermediário, o que requer um detalhamento e preocupação maior por parte da prefeitura, que oscila entre a proposta de "Boulevard" ou de uma grande "Rambla", como já apresentado na descrição.

O resultado dos trabalhos acadêmicos contidos na publicação "Reforma de la Diagonal de Barcelona: Espacio público + transporte colectivo" (2010) enfatiza a necessidade de se abordar a reordenação da mobilidade no Ensanche como condição prévia e indispensável para a reforma do tramo central da Avenida no seu papel de novo centro metropolitano. A prefeitura, dentro da mesma proposta de priorizar pedestres e transporte coletivo, concebe a Avenida Diagonal como agente de um papel mais urbano, com caráter local, não buscando uma atuação metropolitana para a via articuladora.

Poderíamos concluir que todos os estudos acadêmicos, os projetos institucionais e os projetos executados contemplam a avenida como um exemplo de integração modal ao propor uma grande via que articula e prioriza o transporte público de massa nos trechos já implantados, combinando vias exclusivas para 0 ônibus e bonde (VLT), e grandes passeios para pedestres, permitindo a circulação dos veículos privados, mas não relevando a sua utilização. A integração com o metrô acontece ao longo da avenida, em acessos bem organizados e projetados para a acessibilidade universal. Conclui-se que a cidade ainda carece de um planejamento integrado para os transportes, mas coloca-se que no trecho Glorias-Fórum a Avenida Diagonal apresenta uma organização e integração modal qualificada.

\section{CONSIDERAÇÕES FINAIS}

Abordamos neste trabalho, através de uma breve síntese histórica, de descrição dos sistemas e de um pequeno diagnóstico, as principais modalidades de transporte de Barcelona e sua Região Metropolitana. Após a revisão bibliográfica, pode-se concluir que a Área Metropolitana de Barcelona (2011), instituição encarregada do planejamento metropolitano da região, vem coordenando as municipalidades em relação a investimentos, tanto em planejamento de estratégias de transporte como em material rodante, como forma de superar as restrições à mobilidade da região. Em relação à mobilidade urbana e metropolitana, os autores estudados são unânimes em colocar que a região analisada ainda necessita de um planejamento 
global e mais integrado dos sistemas de transporte que atualmente não se encontram em sistema de rede, apesar da terminologia rede de transportes ser bastante utilizada nos vários textos.

Uma verdadeira rede de transportes deve ser definida por um ou vários campos de centralidade, que adotem formas e posições específicas sobre o território, sendo as estações lugares privilegiados no espaços e portanto se agrupam em forma de constelação, com densidades e assimetrias significativas. Entretanto, Barcelona e sua região metropolitana não apresentam tal sistema, sendo que Parcerisa e Ventós (2002) são incisivos em afirmar que as estratégias de implantação de serviços, de equipamentos, das áreas de atividades e de residência seguem desvinculadas da oferta de transporte massivo público, que se distribui de forma aleatória sobre o tecido urbano. Então, se poderia dizer que o crescimento global da mobilidade em Barcelona não vem acompanhado por um crescimento da oferta de transporte eficaz, comportando a diminuição da participação do transporte público em relação ao transporte privado.

Para Herce (2009), a solução do problema estaria na coordenação dos modos de transporte e na intermodalidade, mas que a mesma só seria eficaz se pensada desde o uso combinado de diferentes sistemas de transporte. Ainda para o autor (2009), o exercício do direito a conexão, a mobilidade das pessoas e do transporte de bens implica a atenção a todas as formas de deslocamento, o que significa um cuidado preferencial das formas que consomem menos energia e criam menos dependência, e que obriga a relevar o tipo de infraestruturas que oferecem tais características e efeitos e na atenção à gestão do espaço. Este direito supõe a intervenção da administração pública para garantir a oferta de espaços públicos adaptados a cada forma de mobilidade e de sistemas de transporte. Implica uma importante mudança de enfoque, que leve em consideração as consequências do consumo energético com emissões de forte impacto ambiental de um modelo baseado fundamentalmente no automóvel.

Mas um exemplo de tentativa de integração modal e de reconversão de valores de mobilidade para o século XXI poderia ser intuído por alguns trechos da Avenida Diagonal, e que seriam exemplos que poderiam inspirar novas urbanizações em cidades em expansão. Neste sentido, podemos colocar que os critérios orientados por Font (2010) para uma mudança de paradigma na relação à infraestrutura urbana e a sua mobilidade, com a priorização do transporte público de massa, dos pedestres e dos meios de circulação que não abranjam o transporte privado assim como um sistema coordenado de transporte público implementado como estratégia urbana foram, de alguma forma, contemplados em parte da Avenida Diagonal.

\section{BIBLIOGRAFIA}

ÀREA METROPOLITANA DE BARCELONA. Entitat metropolitana del transporte in Memòria, àrea metropolitana de Barcelona, 2007-2011. Barcelona: Àrea Metropolitana de Barcelona, 2011.

BRITO, João Paulo Camboin de. Modelo de mobilidadeem Barcelona: a prolongação da diagonal e o VLT. Actas del XI Coloquio Internacional de Geocrítica, Buenos Aires, Universidade de Buenos Aires, 2010.

FONT, Antonio, CASTIÑEIRA, Isabel, MAGRINYÀ, Francesc, MAYORGA, Miguel Y. Reforma de la Diagonal de Barcelona: Espacio público + transporte colectivo. Barcelona: Oficina Multimèdia i Publicaciones, ETSAV, 2010.

FONT, Antonio. Region urbana de Barcelona: de la ciudad compacta a los territórios metropolitanos in Transformaciones territoriales en las regiones urbanas de la Europa Meridional. Madrid: Ministério de la Vivienda, 2007.

HERCE, Manuel, MAGRINYÀ, Francesc, MIRO, Joan. L'espaiurbà de la mobilitat. Barcelona: Edicions UPC, 2007.

HERCE, Manuel. El derecho a la movilidad in Sobre la movilidad en la ciudad. Propuestas para recuperar un derecho ciudadano. Barcelona: Reverté, S.A, 2009.

HERCE, Manuel. El reto del transporte colectivo: mejoras en su oferta como herramienta, in Sobre la movilidad en la ciudad. Propuestas para recuperar un derecho ciudadano. Barcelona: Reverté, S.A, 2009.

MAGRINYA, Francesc, Repensar a Diagonal hoy es repensar El Ensanche de Barcelona desl siglo XXI, in FONT, Antonio, CASTIÑEIRA, Isabel, MAGRINYÀ, Francesc, MAYORGA, Miguel Y. Reforma de la Diagonal 
de Barcelona: Espacio público + transporte colectivo. Barcelona: Oficina Multimèdia i Publicaciones, ETSAV, 2010.

MAYORGA, Miguel Y. La Avenida diagonal: proyecto urbano. Nuevo modelo de movilidad y nuevo modelo de ciudad. In in FONT, Antonio, CASTIÑEIRA, Isabel, MAGRINYÀ, Francesc, MAYORGA, Miguel Y. Reforma de la Diagonal de Barcelona: Espacio público + transporte colectivo. Barcelona: Oficina Multimèdia i Publicaciones, ETSAV, 2010.

NAVAS, Teresa. ¿Que es una via de comunicación? A propósito de la movilidad y el territorio según Ildefonso Cerdà in FUSTER SOBREPER, J. La Agenda Cerdá. Construyendo la Barcelona Metropolitana. Barcelona: Ajuntamiento de Barcelona, LUNWERG Editores, IntitutCerdá, 2010.

PARCERISA, Josep, VENTÓS, MariaRubert. Metro: galàxiesmetropolitanes. Barcelona: Edicions UPC, 2002. Volume 7 da Col-lecióD’Árt, Disseny, Arquitectura/Urbanisme Series.

SCHEIN, Augusto Leonardo. Sistema de informaçãoaousuário como estratégia de fidelização e atração.Porto Alegre: Universidade Federal do Rio Grande do Sul, 2003. Dissertação de mestrado. Programa de Pós-GraduaçãoemEngenharia de Produção.

SOLANS, Juan Antonio. Barcelona. Planeamiento del metropolitano versus planeamiento metropolitano.In Movilidad Urbana no 026763. Barcelona: Colegio Oficial de Arquitectos de Cataluña y Baleares, 1972.

SORT, Jordi Julià. Barcelona in Redes metropolitanas, metropolitannetworks. Barcelona: Editorial Gustavo Gili, 2006.

\section{Fontes eletrônicas:}

http://www.lavanguardia.com/vida/20120314/54268820792/taxistas-barcelona-sants-estacio.html LA VANGUARDIA. Taxistas de Barcelona reclaman poder parar delante de la estación de Sants. Março de 2012. (consultaem12/03/2013).

www.vtpi.org/elasticities.pdfRoger. MACKETT, Roger. "Polices to Attract Drivers Out of Their Cars forTransportationElasticities-VictoriaTransport PolicyInstitutein L.Mackett(2001), "Polices to Attract Drivers Out of Their Cars For (consulta em08/01/2013).

http://divulgamat2.ehu.es/divulgamat15/index.php?option=com_content\&view=article\&id=13057\&showall=1 MUZÁS, José Mํㅡㄴ Sorando. Las ciudades geométricas. Setembro de 2011. (consultaem 12/03/2013).

www.iermb.uab.es/.../revistaPapers. PRAT, Jordi. El sistema ferroviario en la configuración de la región de Barcelona.Institutd'Estudisregionals i Metropolitans de Barcelona, 1994..(consultaem 18/01/2013).

www.docutren.com/.SALAS SUADE, Rosa. Evolución de la red ferroviaria e influencia de esta sobre el crecimiento urbano en Barcelona y su área metropolitana.(consultaem17/01/2013).

http://www.tmb.cat/img/genplano.pdf.TRANSPORTES METROPOLITANOS DE BARCELONA. Mapa das linhas de metrô de Barcelona. Barcelona, Espanha. (consulta em 12/03/2013).

http://www.vivagreen.mobi/?page=noticias\&id=842.VIVAGREEN. Boas práticas de mobilidade urbana no Brasil e no mundo.Dezembro De 2012. (consulta em 12/03/2013). 